Research Paper

\title{
Maternal exposure to di-n-butyl phthalate (DBP) induces renal fibrosis in adult rat offspring
}

\author{
Yi-Ping Zhu ${ }^{1, *}$, Lei Chen ${ }^{1, *}$, Xing-jie Wang ${ }^{1, *}$, Qi-Heng Jiang ${ }^{3, *}$, Xiao-Yu Bei ${ }^{1}$, \\ Wen-Lan Sun ${ }^{2}$, Shu-Jie Xia ${ }^{1}$, Jun-Tao Jiang ${ }^{1}$ \\ ${ }^{1}$ Department of Urology, Shanghai General Hospital, Shanghai Jiao Tong University School of Medicine, Shanghai 200080, China \\ ${ }^{2}$ Department of Geriatrics, Shanghai General Hospital, Shanghai Jiao Tong University School of Medicine, Shanghai 200080, China \\ ${ }^{3}$ Medical Services Section, Shanghai General Hospital, Shanghai Jiao Tong University School of Medicine, Shanghai 200080, China \\ *These authors contributed equally to this work
}

Correspondence to: Jun-Tao Jiang, email: jjturologist@126.com

Shu-Jie Xia, email: xsjurologist@126.com

Keywords: renal fibrosis, kidney dysplasia, di-n-butyl phthalate (DBP), oxidative stress, environmental endocrine-disrupting compounds (EEDs)

Received: November 30, 2016

Accepted: March 01, 2017

Published: March 10, 2017

Copyright: Zhu et al. This is an open-access article distributed under the terms of the Creative Commons Attribution License (CC-BY), which permits unrestricted use, distribution, and reproduction in any medium, provided the original author and source are credited.

\section{ABSTRACT}

This study was to determine the impact of maternal exposure to di-n-butyl phthalate (DBP) on renal development and fibrosis in adult offspring. Pregnant rats received DBP at a dose of $850 \mathrm{mg} / \mathrm{kg} \mathrm{BW} /$ day by oral perfusion during gestational days 14-18. In DBP exposed newborn offspring, gross observation and histopathological examination revealed the dysplasia of kidney. The expression of genes related to renal development was also changed. In DBP exposed adult offspring, histopathological examination and Masson's trichrome staining revealed the pathological changes of renal fibrosis. Furthermore, higher expression levels of transforming growth factor- $\beta$ (TGF- $\beta$ ) and alpha-smooth muscle actin (a-SMA) were also detected. In vitro studies reveal that DBP promoted the activation of NRK49F cells and G2/M arrest in NRK52E cells at a sublethal dose. The effect of DBP on these cell lines was linked to the generation of oxidative stress. In addition, DBP induced oxidative stress in both renal fibroblasts and tubular epithelial cells, whereas vitamin $\mathrm{C}$ ameliorated the changes caused by DBP. In conclusion, our results showed that prenatal exposure to DBP may generate oxidative stress in both renal fibroblasts and tubular epithelial cells, leading to kidney dysplasia and renal fibrosis.

\section{INTRODUCTION}

It is estimated that $8-16 \%$ of adults in the world have chronic kidney disease (CKD), which is characterized by relentless deposition of extracellular matrix and progressive tubulointerstitial fibrosis (TIF). TIF eventually leads to end-stage renal disease, which seriously affects the quality of life and results in heavy financial burden [2-4]. Therefore, exploring of the pathologic mechanisms of renal fibrosis is essential for developing new therapeutic targets to prevent CKD.

In addition to the two conventional factors, genes and the environment, which contribute to the etiology of diseases, increasing evidence suggests that prenatal (intrauterine) procedures have a profound effect on subsequent organ function and adult disease [5]. The
'Developmental Origins of Health and Adult Disease' (DOHAD) hypothesis proposes that environmental stimulation on organ development in uterus may have permanent adverse effects and increase risks of specific diseases in adult life [6-7]. Many studies have shown that intrauterine malnutrition, infection, drugs, toxins and stress are all determinants of the intrauterine environment [8-11]. The role of an adverse intrauterine environment in developmental programming can be applied to CKD in the adult [12]. Among all factors identified, low birth weight (LBW) is the most prominent factor for DOHAD. It is reported that $\mathrm{LBW}$ is related to the increased risk of adultonset diseases (including renal function disorder) [13].

DBP is known as one of representative environmental endocrine-disrupting compounds (EEDs) and is ubiquitously present in a variety of consumer 
products [14]. Recent evidence indicates that DBP exposure in utero has an adverse influence on the male reproductive system, leading to spermatogenesis dysfunction, cryptorchidism and hypospadias [15-21]. Our previous studies showed that prenatal DBP exposure can result in hypospadias or anorectal malformations (ARMs) in male offspring [20, 22-24]. We found that DBP-induced ARMs in male offspring were accompanied by a poor general condition, LBW and significantly decreased organ/body weight ratios of the kidney [25]. Furthermore, the number of glomeruli shows a positive correlation with kidney weight [26]. Our recent finding suggests that androgen and its receptor (AR) and Fgf10/ Fgfr2 may be involved in kidney abnormal development induced by DBP [27].

In this study, we used an optimized treatment regimen to show that maternal DBP exposure can induce kidney dysplasia in rat offspring on postnatal day 1 (PND1) and renal fibrosis in adult offspring. In vitro, DBP promoted the activation of NRK49F cells and G2/M arrest in NRK52E cells at a sublethal dose. The effect of DBP on these cell lines was linked to the generation of oxidative stress. In addition, our experimental results showed that DBP induced oxidative stress in both renal fibroblasts and tubular epithelial cells, while vitamin $\mathrm{C}$ ameliorated the changes caused by DBP. These results show that prenatal DBP exposure may generate oxidative stress in both renal fibroblasts and tubular epithelial cells and eventually lead to kidney dysplasia and renal fibrosis.

\section{RESULTS}

\section{Maternal exposure to DBP induces kidney dysplasia in rat offspring on PND1}

On PND1, the body weight (Figure 1A) and the size (Figure 1B) of the kidneys in the DBP-exposed group were significantly less than those in the DBPunexposed controls. Compared with the DBP-unexposed control group, the organ/body weight ratio of the kidneys in the DBP-exposed group was decreased (Figure 1C). Histopathological examination of kidney tissue showed no pathological variation in control group and swelling of the glomerular tufts in the DBP-exposed group. Forkhead box D1 (Foxd1), wingless-type MMTV integration site family, member 11 (Wnt11), paired box 2 (Pax2) and glial cell derived neurotrophic factor (Gdnf) are related to renal development. The reduced mRNA expression of these genes was found in the DBP-exposed group on PND1. In addition, maternal DBP exposure led to upregulation of the mRNA expression of other genes, including bone morphogenetic protein 4 (Bmp4), cadherin 11 (Cdh11), tyrosine 3-monooxygenase/tryptophan 5-monooxygenase activation protein, beta (Ywhab) and calmodulin 1 (Calm1) (Figure 1E).

\section{Maternal exposure to DBP leads to renal fibrosis in adult offspring}

Histopathological examination of kidney tissue showed that the kidneys of the DBP-exposed group developed tubular damage, with the presence of tubular atrophy, compression of tubular cells, widening of intertubular spaces and thickening of the tubular basement membrane. In addition, Masson trichrome staining showed that, compared with control rats, DBP-exposed rats exhibited significantly increased interstitial extracellular matrix accumulation (Figure 2A). Immunohistochemical staining demonstrated that the abundance of alpha-smooth muscle actin ( $\alpha$-SMA), fibronectin and transforming growth factor- $\beta$ (TGF- $\beta$ ) protein was significantly higher in the kidneys of DBP-exposed adult offspring than in those of unexposed controls (Figure 2B-2C). Quantitative determinations using Western blot and real-time PCR produced similar results (Figure 2D-2F).

\section{DBP promotes the proliferation and activation of NRK49F cells at a sublethal dose}

To determine the effect of DBP on renal fibroblasts in vitro, NRK49F cells, a rat kidney interstitial fibroblast cell line, were exposed to various concentrations of DBP. At a sublethal dose $(1,10 \mu \mathrm{mol} / \mathrm{L}), \mathrm{DBP}$ was capable of promoting the proliferation of NRK49F cells, whereas higher doses $(100 \mu \mathrm{mol} / \mathrm{L})$ caused a sharp drop in cell number (Figure 3A). To confirm the induction of apoptosis among NRK49F cells exposed to different concentrations of DBP, we stained the cells with Hoechst 33342 dye. DBP at a higher dose $(100 \mu \mathrm{mol} / \mathrm{L})$ induced apoptosis in NRK49F cells, whereas DBP at a sublethal dose $(1,10$ $\mu \mathrm{mol} / \mathrm{L}$ ) had few effects on apoptosis in NRK49F cells (Figure 3B). Thus, we conclude that DBP promotes the proliferation of renal fibroblast NRK49F cells at a sublethal dose. In addition, in the NRK49F cells exposed to DBP at a sublethal dose $(10 \mu \mathrm{mol} / \mathrm{L})$, the expression levels of $\alpha$-SMA, fibronectin and TGF- $\beta$ were increased at both the protein and mRNA levels, compared to the control group (Figure 3C-3E).

\section{DBP inhibits NRK52E cell growth without apoptosis at a sublethal dose}

To determine the effect of DBP on renal tubular epithelial cells in vitro, NRK52E cells were exposed to various concentrations of DBP. DBP at a sublethal dose $(1,10 \mu \mathrm{mol} / \mathrm{L})$ had only a small effect on cell number, whereas higher doses $(100 \mu \mathrm{mol} / \mathrm{L})$ caused a significant decrease in cell number (Figure 4A). To test whether DBP induced apoptosis in NRK52E cells, we stained NRK52E cells with Hoechst 33342 dye. DBP at a higher dose $(100 \mu \mathrm{mol} / \mathrm{L})$ induced apoptosis of NRK52E cells, 
whereas DBP at a sublethal dose $(1,10 \mu \mathrm{mol} / \mathrm{L})$ had few effects on apoptosis in NRK52E cells (Figure 4C). Thus, we conclude that DBP inhibits the proliferation of NRK52E cells without cell death at a sublethal dose.

\section{DBP induces $\mathrm{G} 2 / \mathrm{M}$ arrest and the overproduction of TGF- $\beta$ in NRK52E cells}

With the Ki67/ the phosphorylation of histone H3 at Ser10 (p-H3) double staining, we evaluated whether NRK52E cells arrest at the G2/M phase. Among all proliferative NRK52E cells (Ki67-positive), the percentage of NRK52E cells exposed to DBP in the $\mathrm{G} 2 / \mathrm{M}$ phase ( $\mathrm{p}-\mathrm{H} 3$ positive) was increased significantly, compared with the percentage of the DBP-unexposed controls (Figure 4B). Furthermore, Western blot analysis and real-time PCR showed that the expression of TGF- $\beta$ was significantly higher in the NRK52E exposed to DBP at a sublethal dose (Figure 4D-4F). Positive regulation of the cell cycle is mediated by the cyclin-dependent kinases. p21 is one of the CKD inhibitors and belongs to the Cip/ Kip family [28]. The expression of p21 protein was investigated in NRK52E cells by Western blot analysis, and the results showed significantly increased expression of p21 in DBP-exposed NRK52E cells. Quantitative determination of the mRNA level by real-time PCR showed similar results (Figure 4D-4F).

\section{DBP generates oxidative stress in NRK49F and NRK52E cells}

NRK49F and NRK52E cells were incubated with DCFH-DA to measure the intracellular reactive oxygen species (ROS). The quantity of ROS in these
A

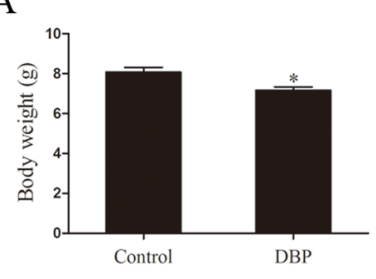

B

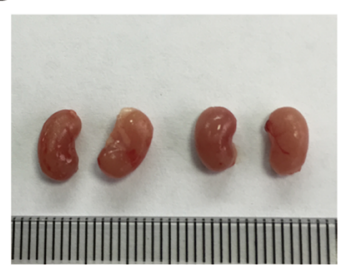

D

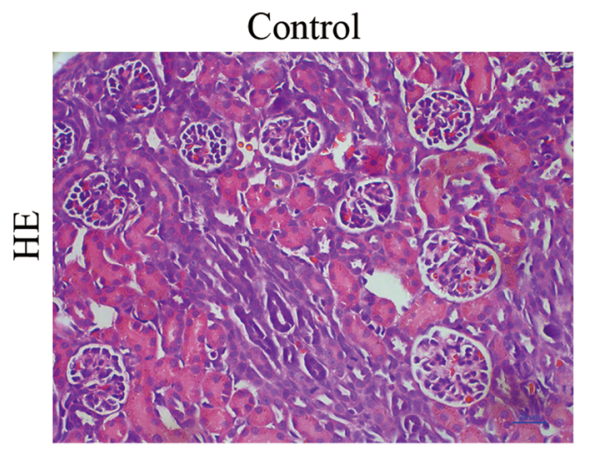

$\mathrm{E}$

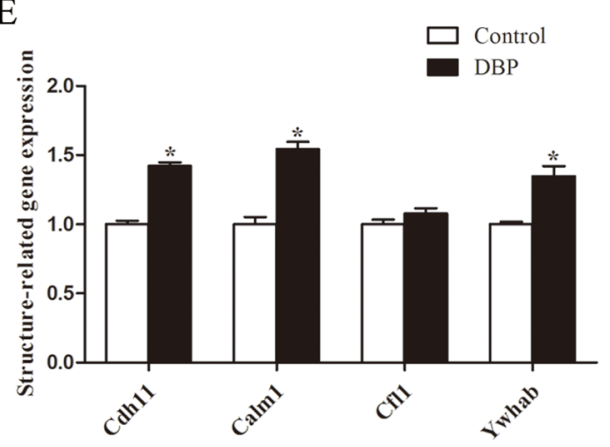

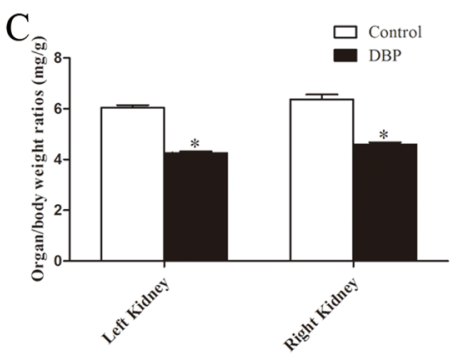

DBP
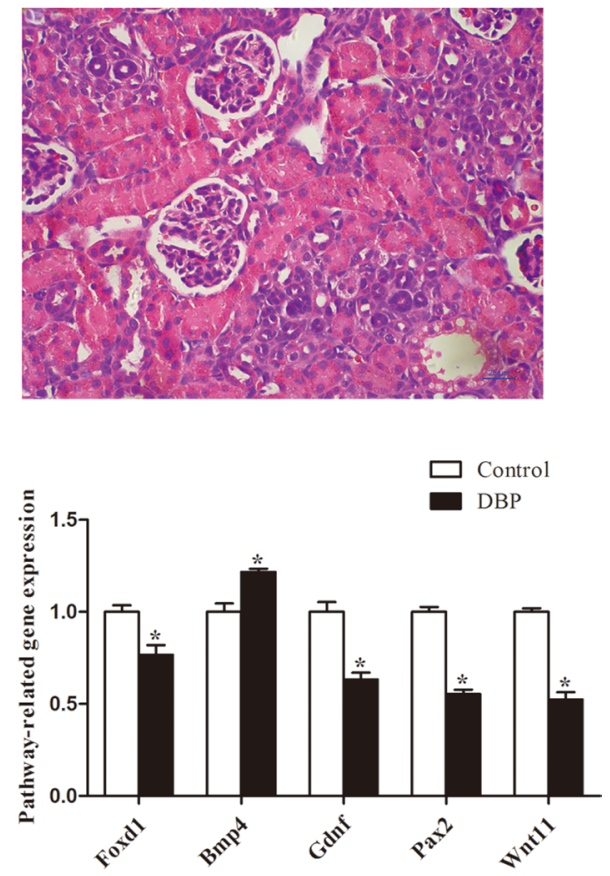

Figure 1: Maternal exposure to DBP induces kidney dysplasia in rat offspring on PND1. (A) The body weight of the rat offspring in the DBP-exposed group and DBP-unexposed controls on PND1. (B) Gross images of the kidneys in the DBP-exposed group and DBP-unexposed controls on PND1. (C) The organ/body weight ratio of the kidneys in the DBP-exposed group and the DBP-unexposed control group on PND1. (D) H\&E stained images of kidney tissue showed differences between the control and DBP-exposed offspring on PND1. (E) Real-time PCR assessed the expression of genes involved in renal development (Foxd1, Gdnf, Pax2, Wnt11, Bmp4, Cdh11, Calm1, Cfl1, Ywhab) in the kidneys of DBP-exposed rats and DBP-unexposed controls on PND1. Data represent mean \pm SD. $n=6$ rats per group, ${ }^{*} P<0.05$. 
cells increased significantly after treatment with DBP $(P<0.05)$ (Figure 5A-5B). The result suggested that DBP induced the generation of ROS in NRK49F and NRK52E cells, which was obvious in higher concentration of DBP.

\section{DBP reduces the expression of the gene responsible for the prevention of oxidative activity in NRK49F and NRK52E cells}

The impact of DBP on the antioxidant activity of genes in NRK49F and NRK52E cells was analyzed by real-time PCR. We found that DBP significantly reduced the expression of antioxidant genes such as glutathione peroxidase $1(G p x 1)$, catalase $(C a t)$, glutathione reductase $(G R)$ and glutathione-s-transferase $(G s t)$. Expression of these antioxidant genes was decreased with increasing doses of DBP (Figure 5C-5D).

\section{The effect of DBP on NRK49F and NRK52E cells can be reversed by vitamin $C$}

NRK49F and NRK52E cells were pretreated with vitamin $\mathrm{C}$, an important water-soluble antioxidant. The results showed that vitamin $\mathrm{C}$ could protect these cells against the oxidative stress induced by DBP. The quantity of ROS decreased significantly in NRK49F and NRK52E cells co-incubated with DBP and vitamin C compared to that in cells treated with DBP alone (Figure 5E-5F). The expression of antioxidant genes was also increased in the these cells co-incubated with DBP and vitamin $\mathrm{C}$ (Figure 5G-5H). Furthermore, vitamin $\mathrm{C}$ almost completely blocked the $\mathrm{G} 2 / \mathrm{M}$ arrest induced by DBP (Figure 4B). The expression of $\alpha$-SMA, fibronectin and TGF- $\beta$ in NRK49F cells decreased to some degree with vitamin $\mathrm{C}$ pretreatment (Figure 3C-3E). In
A

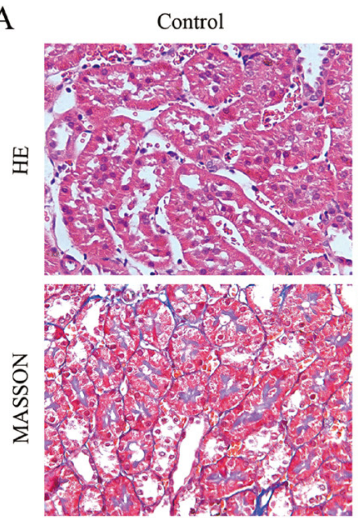

$\mathrm{C}$

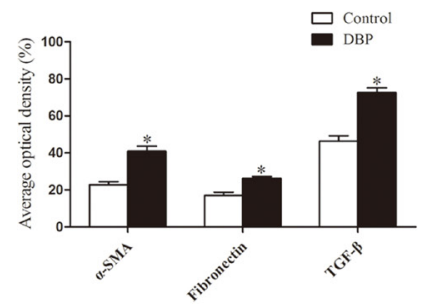

$\mathrm{D}$

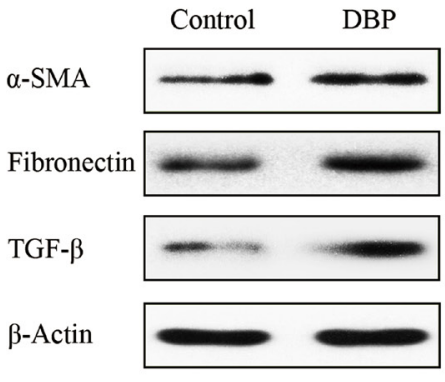

DBP

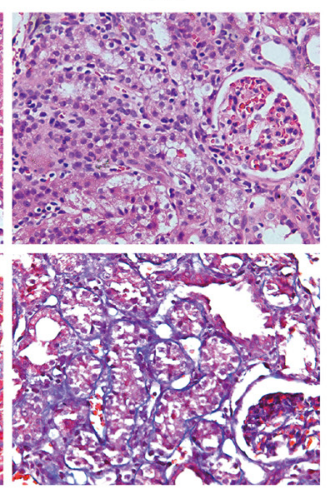

Control
DBP

B
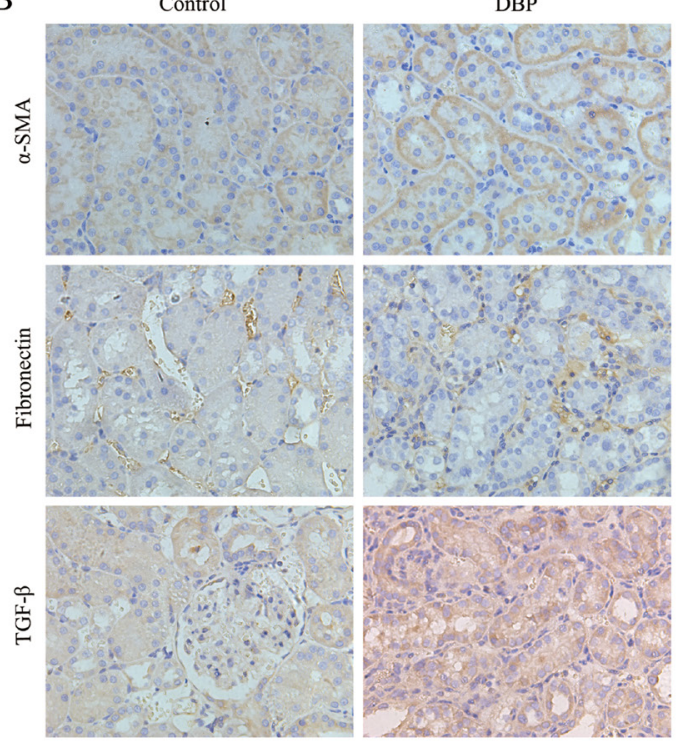

F

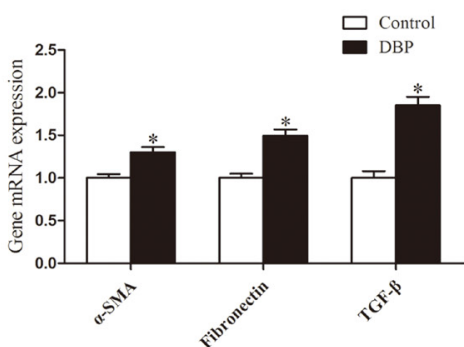

Figure 2: Maternal exposure to DBP leads to renal fibrosis in adult offspring. (A) H\&E and Masson trichrome stained images of kidneys in the DBP-exposed adult offspring and DBP-unexposed controls. (B) Represented immunohistochemical localization of $\alpha$-SMA, fibronectin and TGF- $\beta$ in the kidneys of DBP-exposed adult offspring and unexposed controls. (C) The average optical density of $\alpha$-SMA, fibronectin and TGF- $\beta$ in the kidneys of DBP-exposed adult offspring and unexposed controls. (D) Western blot showing different $\alpha$-SMA, fibronectin and TGF- $\beta$ protein levels of kidneys in DBP-exposed adult offspring and unexposed controls. (E) Densitometric quantification of $\alpha$-SMA, fibronectin and TGF- $\beta$ proteins in the kidneys of DBP-exposed adult offspring and unexposed controls. (F) Realtime PCR assessed the expression of $\alpha$-SMA $(A c t a)$, fibronectin $(F n)$ and TGF- $\beta(T g f b)$ in the kidneys of DBP-exposed adult offspring and unexposed controls. Data represent mean \pm SD. $n=6$ rats per group, ${ }^{*} P<0.05$. 
addition, the overproduction of TGF- $\beta$ in NRK52E cells induced by DBP was reversed by treatment with vitamin C (Figure 4D-4F).

\section{DISCUSSION}

The present study demonstrates that maternal DBP exposure can induce kidney dysplasia in offspring on PND1 and renal fibrosis in adult offspring. In vitro, DBP promoted the activation of NRK49F cells and G2/M arrest in NRK52E cells at a sublethal dose. The effect of DBP on these cell lines was linked to the generation of oxidative stress, and treatment with vitamin $\mathrm{C}$ could ameliorate the changes caused by DBP.

DBP is an estrogen-like chemical that is ubiquitously present in a variety of consumer products and can also be released into the environment. Most studies indicate that DBP has an adverse influence on the reproductive system. Our previous studies have shown that maternal exposure to DBP can induce decreased organ/body weight ratios in the kidney [25]. In the present study, we detected swelling of the glomerular tufts in the kidney of the DBP-exposed group on PND1 by histological examination. Foxd1, Gdnf, Pax 2 and $W n t 1$ are related to branching of ureteric bud and inducing nephron [29]. In the study, we found maternal DBP exposure led to reduced Foxd1, Gdnf, Pax 2 and Wnt1 mRNA expressions. Bmp4 can inhibit Gdnf signaling, which is consistent with our finding in the study. The upregulation of the mRNA expression of structure-related genes Cdh11, Calm1 and Ywhab in rat offspring on PND1 suggests the renal development is incomplete [29]. Maternal exposure to DBP also led to renal fibrosis in adult offspring. Histopathological examination of the kidney tissue showed that the kidneys of the DBP-exposed group developed tubular damage and increases in the interstitial space. In addition to interstitial extracellular matrix accumulation, proteins such as $\alpha$-SMA, fibronectin, and TGF- $\beta$ were significantly increased in the DBP-exposed group.

A
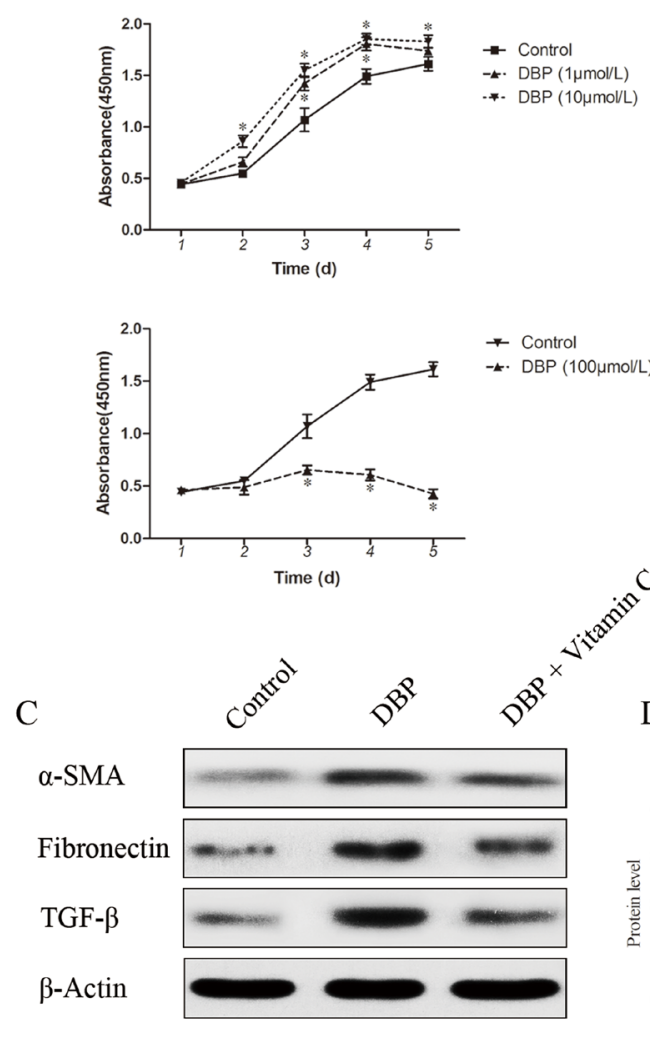

- Control -2. DBP $(1 \mu \mathrm{mo} / \mathrm{L})$ .*. DBP (10umo/L)
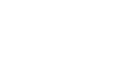

B

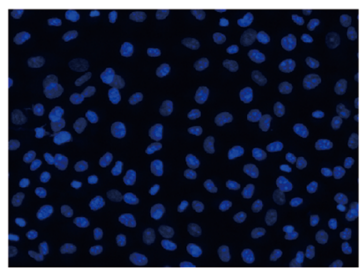

$\operatorname{DBP}(10 \mu \mathrm{mol} / \mathrm{L})$

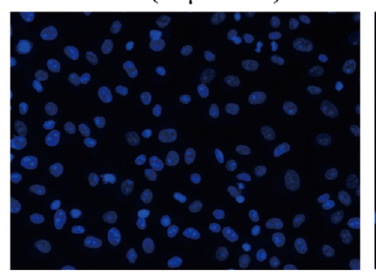

$\operatorname{DBP}(1 \mu \mathrm{mol} / \mathrm{L})$

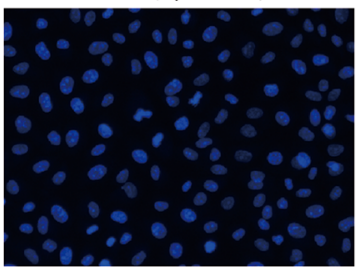

$\operatorname{DBP}(100 \mu \mathrm{mol} / \mathrm{L})$

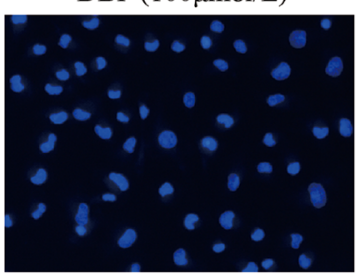

$\mathrm{D}$

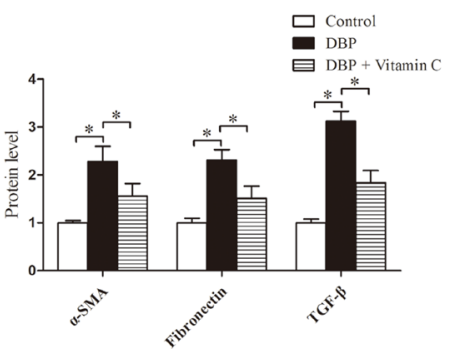

E

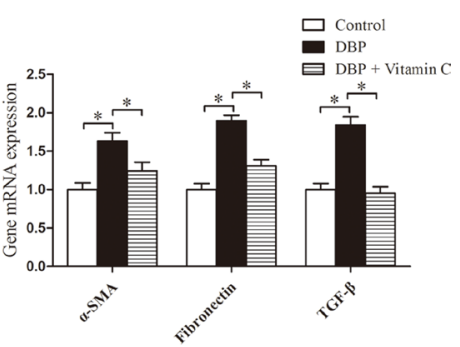

Figure 3: DBP promotes the proliferation and activation of NRK49F cells at a sublethal dose. (A) CCK-8 cell proliferation assays showing different proliferation between NRK49F cells exposed to various concentrations of DBP $(1,10,100 \mu \mathrm{mol} / \mathrm{L})$. (B) Hoechst 33342 dye stained images of NRK49F cells exposed to various concentrations of DBP $(1,10,100 \mu$ mol/L). (C) Western blot showing different $\alpha$-SMA, fibronectin and TGF- $\beta$ protein levels of NRK49F cells in DBP-exposed, vitamin C-exposed group and unexposed controls. (D) Densitometric quantification of $\alpha$-SMA, fibronectin and TGF- $\beta$ proteins levels of NRK49F cells in DBP-exposed, vitamin C-exposed group and unexposed controls. (E) Real-time PCR assessed the expression of $\alpha$-SMA (Acta), fibronectin (Fn) and TGF- $\beta$ $(T g f b)$ of NRK49F cells in DBP-exposed, vitamin C-exposed group and unexposed controls. Data represent mean \pm SD. $n=6$ rats per group, ${ }^{*} P<0.05$. 
A recent study showed that the activities of antioxidant enzymes and total antioxidant capacity in serum decreased significantly after treatment with DBP [30]. Another ATM substrate Chk2-interacting Zn(2+)finger knockout mouse study comfirmed that oxidative damage can lead to severe organ development defects [31]. These results indicate that oxidative stress could be one of the mechanisms responsible for the development DBP-induced kidney dysplasia. It has been shown that BPA, another EED, can down-regulate the antioxidant gene expression and induce the production of ROS [32].
The present study demonstrates that in NRK49F and NRK52E cells, the quantity of ROS increased and the expression of antioxidant genes (Gpx1, Cat, Gst, and GR) decreased significantly after treatment with DBP.

Aberrant activation of fibroblasts to myofibroblasts lead to relentless deposition of extracellular matrix, including $\alpha$-SMA and fibronectin. This process is closely related to oxidative stress. TGF- $\beta 1$ can activate fibroblasts to myofibroblasts and promote the development of renal fibrosis via Smad-dependent and Smad-independent signaling pathways. $[3,33]$. In our study, the expression
A
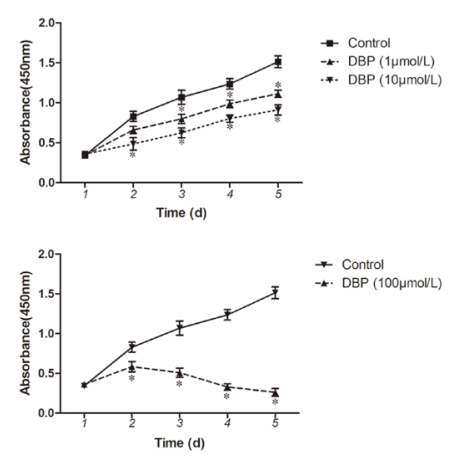

C

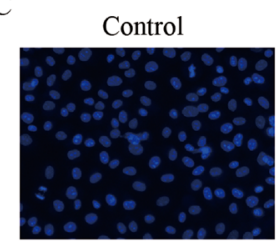

DBP $(10 \mu \mathrm{mol} / \mathrm{L})$
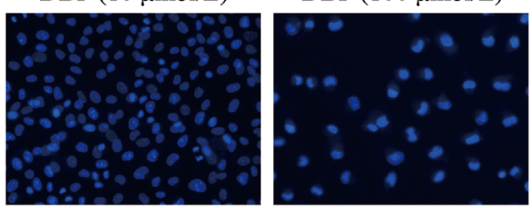

$\mathrm{D}$
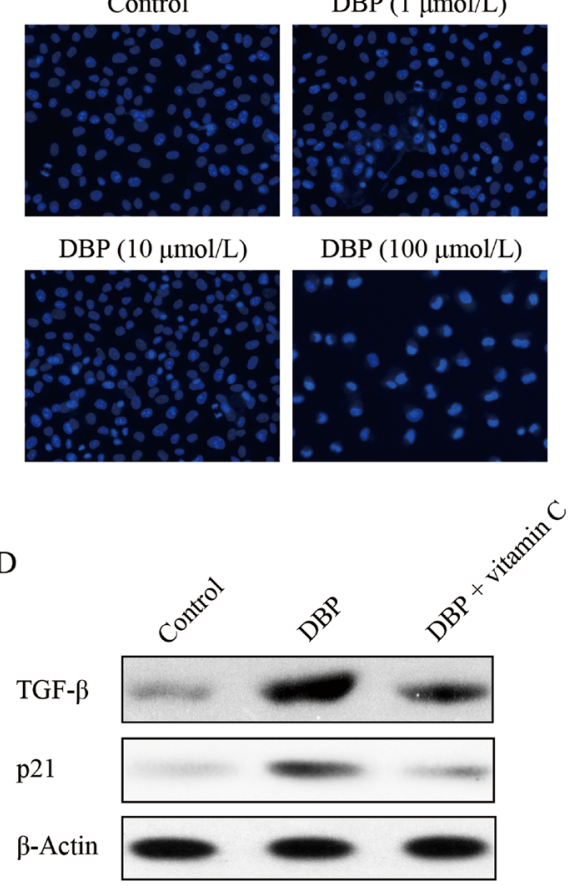

$\operatorname{DBP}(100 \mu \mathrm{mol} / \mathrm{L})$
B
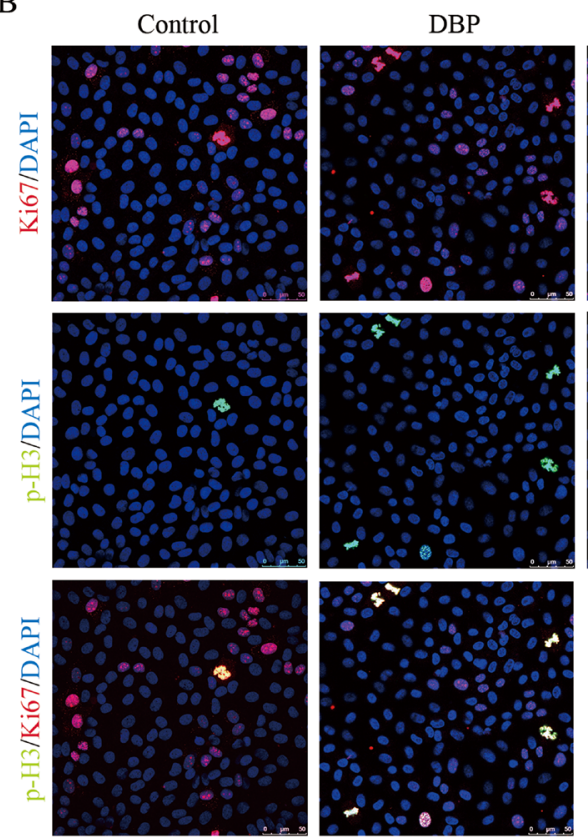

$\mathrm{DBP}+$ vitamin $\mathrm{C}$
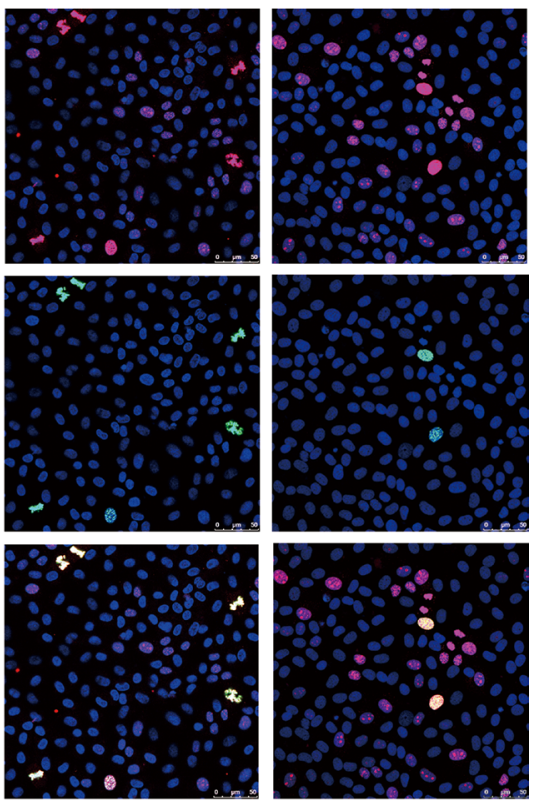

E
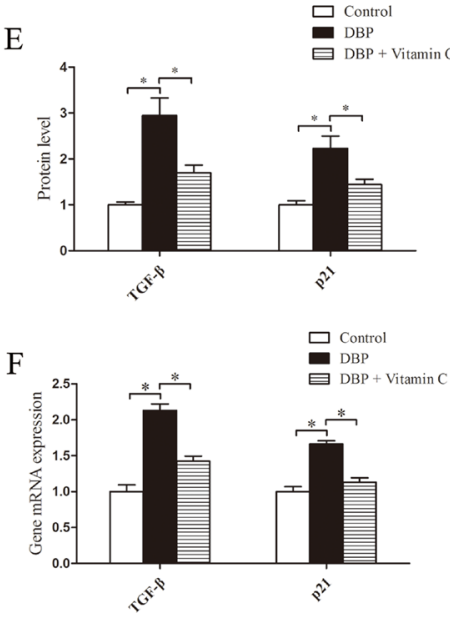

Figure 4 DBP inhibits NRK52E cell growth and induces G2/M arrest and the overproduction of TGF- $\beta$ in NRK52E cells at a sublethal dose. (A) CCK-8 cell proliferation assays showing different proliferation between NRK52E cells exposed to various concentrations of DBP $(1,10,100 \mu \mathrm{mol} / \mathrm{L})$. (B) Dual immunofluorescence of Ki67 (red) and p-H3 (green) in NRK52E cells of DBPexposed, vitamin C-exposed group and unexposed controls. DAPI (blue) was used for nuclear staining. (C) Hoechst 33342 dye stained images of NRK52E cells exposed to various concentrations of DBP $(1,10,100 \mu \mathrm{mol} / \mathrm{L})$. (D) Western blot showing different TGF- $\beta$ and p21 protein levels of NRK52E cells in DBP-exposed, vitamin C-exposed group and unexposed controls. (E) Densitometric quantification of TGF- $\beta$ and p21 protein levels of NRK52E cells in DBP-exposed, vitamin C-exposed group and unexposed controls. (F) Real-time PCR assessed the expression of TGF- $\beta(T g f b)$ and p21(Cdkn1a) of NRK52E cells in DBP-exposed, vitamin C-exposed group and unexposed controls. Data represent mean \pm SD. $n=6$ rats per group, ${ }^{*} P<0.05$. 
levels of $\alpha$-SMA, fibronectin and TGF- $\beta$ were increased in NRK49F cells exposed to DBP at a sublethal dose, which suggests that the activation of renal fibroblasts by DBP leads to renal fibrosis.

In our study, DBP also induced G2/M arrest and the overproduction of TGF- $\beta$ in NRK52E cells. DNA damage caused by oxidative stress is known to lead to G2/M arrest [34]. A recent study revealed the relationship between tubular epithelial cells arrested in the G2/M phase and progression of renal fibrosis. The cell cycle dysregulation in tubular epithelial cells was correlated with overproduction of TGF- $\beta 1$ and led to renal fibrosis, while reversal of $\mathrm{G} 2 / \mathrm{M}$ arrest reduced the production of TGF- $\beta 1$ and attenuated the progression of renal fibrosis [35]. Indeed, tubular epithelial cells arrested in the G2/M phase play a crucial role in the pathogenesis of TIF.

Vitamin $\mathrm{C}$ is one of the most important watersoluble antioxidants. Studies have shown that vitamin C has antioxidant capacities and protective properties against oxidative stress injury caused by ROS [36-37]. Vitamin C has been reported to have a protective effect against renal injury by reducing the oxidative stress caused by hind limb ischemia-reperfusion (I/R) [38]. In our study, the effect of DBP on NRK49F and NRK52E cells could be reversed by treatment with vitamin $\mathrm{C}$. Compared to cells treated with DBP alone, in cells co-incubated with DBP and vitamin $\mathrm{C}$, the quantity of ROS decreased and the expression of antioxidant genes increased significantly. Furthermore, vitamin $\mathrm{C}$ almost completely blocked the $\mathrm{G} 2 / \mathrm{M}$ arrest induced by DBP, and the expression of $\alpha$-SMA, fibronectin and TGF- $\beta$ in NRK49F cells decreased to some degree when the cells were pretreated with vitamin $\mathrm{C}$. In addition, TGF- $\beta$ overproduction in NRK52E cells induced by DBP could be reversed by vitamin $C$. Together, these findings suggest that the oxidative stress induced by DBP can activate renal fibroblasts, increase the G2/M phase arrest of tubular epithelial cells, and promote progression of renal fibrosis. However, vitamin $\mathrm{C}$ can protect tubular epithelial cells and renal fibroblasts from oxidative stress caused by DBP.

Our studies use an optimized treatment regimen of DBP and are the first to show that maternal exposure to DBP can induce kidney dysplasia in offspring on PND1 and renal fibrosis in adult offspring. In vitro, $\mathrm{DBP}$ could promote the activation of NRK49F cells and G2/M arrest in NRK52E cells at a sublethal dose. The effect of DBP on these cell lines was linked to the generation of oxidative stress. In addition, we determined experimentally that DBP induced oxidative stress in both renal fibroblasts and tubular epithelial cells, whereas vitamin $\mathrm{C}$ ameliorated the changes caused by DBP. These results show that maternal exposure to DBP may generate oxidative stress in both renal fibroblasts and tubular epithelial cells, leading to kidney dysplasia and renal fibrosis. According to the DOHAD hypothesis, maternal exposure to DBP

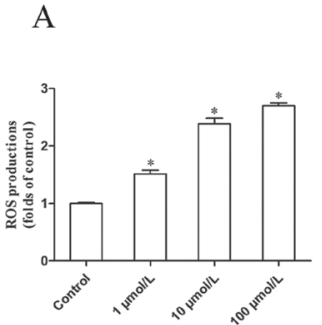

B

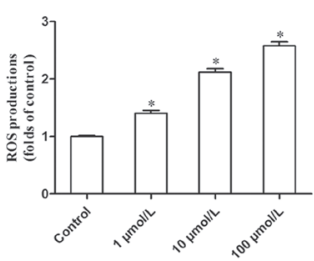

$\mathrm{F}$
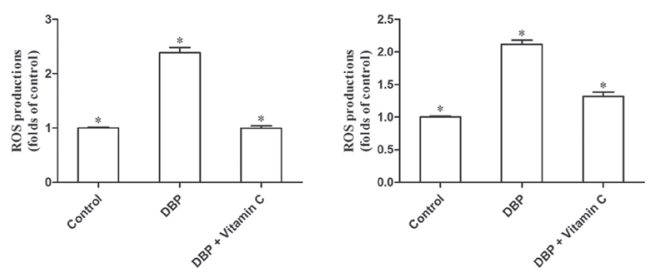

$\mathrm{C}$

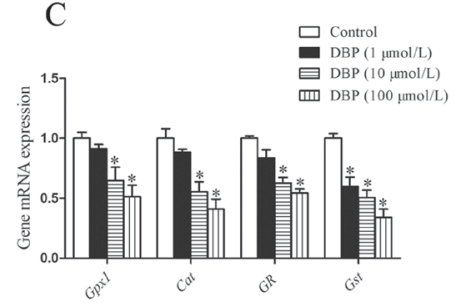

G
$\mathrm{D}$

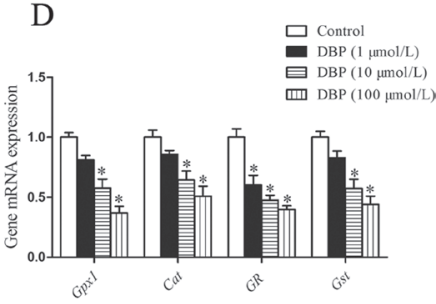

$\mathrm{H}$

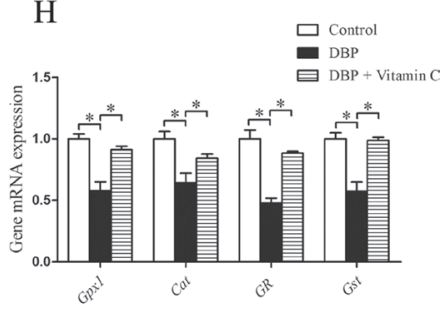

Figure 5: DBP generates oxidative stress and reduces the expression of the gene responsible for the prevention of oxidative activity in NRK49F and NRK52E cells. (A) Measurement of intracellular ROS in NRK49F cells by DCFH-DA dye showed the quantity of ROS increased significantly after treatment with various concentrations of DBP $(1,10,100 \mu \mathrm{mol} / \mathrm{L})$. (B) Measurement of intracellular ROS in NRK52E cells by DCFH-DA dye showed the quantity of ROS increased significantly after treatment with various concentrations of DBP $(1,10,100 \mu \mathrm{mol} / \mathrm{L})$. (C) Real-time PCR assessed the expression of antioxidant genes (Gpxl, Cat, $G R, G s t$ ) of NRK49F cells exposed to various concentrations of DBP $(1,10,100 \mu \mathrm{mol} / \mathrm{L})$. (D) Real-time PCR assessed the expression of antioxidant genes (Gpxl, Cat, GR, Gst) of NRK52E cells exposed to various concentrations of DBP $(1,10,100 \mu \mathrm{mol} / \mathrm{L})$. (E) Measurement of intracellular ROS by DCFH-DA dye in NRK49F cells in DBP-exposed, vitamin C-exposed group and unexposed controls. (F) Measurement of intracellular ROS by DCFH-DA dye in NRK52E cells in DBP-exposed, vitamin C-exposed group and unexposed controls. (G) Realtime PCR assessed the expression of antioxidant genes (Gpxl, Cat, GR, Gst) of NRK49F cells in DBP-exposed, vitamin C-exposed group and unexposed controls. (H) Real-time PCR assessed the expression of antioxidant genes (Gpxl, Cat, GR, Gst) of NRK52E cells in DBPexposed, vitamin C-exposed group and unexposed controls. Data represent mean $\pm \mathrm{SD} . n=6$ rats per group, ${ }^{*} P<0.05$. 
may damage the development of the kidneys in utero and have permanent deleterious effects that increase the risk of CKD (renal fibrosis) during adulthood. Thus, it is important to avoid exposure to DBP and other EEDs during pregnancy to decrease the risk of renal fibrosis. In addition, treatment with vitamin $\mathrm{C}$ during pregnancy may reduce DBP-induced damage to the developing kidneys.

\section{MATERIALS AND METHODS}

\section{Animals}

Sprague-Dawley rats were supplied by Shanghai Laboratory Animal Center. Ethical approval for animal experiments was obtained from the National Institute of Health's Guide for the Care and Use of Laboratory Animals. The method of mating was performed as previously described [23-24, 27]. Twenty successfully mated female rats were distributed into control and DBP-exposed groups randomly. The exposure period and dosage levels of DBP were based on our previous study which effectively induce kidney dysplasia in offspring [27]. Six rats were selected randomly from the DBP-exposed offspring and controls on PND1 and at 18 months, respectively. After measurement of the organ/body weight ratios, the kidneys were collected for subsequent experiments.

\section{Cells and exposure conditions}

NRK49F cells and NRK52E cells were obtained from the American Type Culture Collection (ATCC, Manassas, VA). The cells were maintained in Dulbecco's modified Eagle's medium (DMEM) (HyClone, Logan, UT) supplemented with 10\% fetal bovine serum (FBS) (Gibco, Foster City, CA) and 1\% penicillin/streptomycin (HyClone), and the cells were cultured at $37^{\circ} \mathrm{C}$ in a $5 \%$ $\mathrm{CO}_{2}$ environment. DBP exposure solutions were prepared by dissolving DBP in DMSO and adding this solution to the medium up to concentrations of 1,10 , or $100 \mu \mathrm{mol} / \mathrm{L}$. The concentration of DBP in solvent (DMSO) did not exceed $0.5 \%(\mathrm{v} / \mathrm{v})$. Vitamin C [(+)-sodium L-ascorbate] (Sigma Chemical Co., St. Louis, MO, USA) was dissolved in sterile deionized water. The antioxidant dose of vitamin $\mathrm{C}$ was determined to be $50 \mu \mathrm{M}$. Accordingly, this concentration of vitamin $\mathrm{C}$ was added along with DBP to the culture medium. The solutions of DBP and DBP + vitamin $C$ were sterilized by passage through a $0.22-\mu \mathrm{m}$ filter (Millipore Ireland, Cork, Ireland) before use.

\section{Histology}

The kidney tissues were fixed with formalin. Paraffin-embedded 4-mm kidney sections were stained with hematoxylin-eosin (H\&E) and Masson's trichrome (Sigma-Aldrich).

\section{Western blot}

Western blot was performed as previously described $[23-24,27]$. The primary antibodies against $\alpha$-SMA (1:200, Sigma, MO, USA), fibronectin (1:1000, Abcam, Cambridge, UK), TGF- $\beta$ (1:1000, Cell Signaling Technology, MA, USA), or p21 (1:200, Santa Cruz Biotechnology, CA, USA) were used in the study.

\section{Immunohistochemistry}

Immunohistochemistry was performed as previously described [27]. The primary antibodies against $\alpha$-SMA (1:200, Sigma, MO, USA), fibronectin (1:500, Abcam, Cambridge, UK), and TGF- $\beta$ (1:500, Cell Signaling Technology, MA, USA) were used in the study. After incubation with the primary antibodies, the sections were incubated with secondary antibody (D-3004, Long Island Biotech, Shanghai, China).

\section{Hoechst staining}

After treatment with DBP $(1,10$, or $100 \mu \mathrm{mol} / \mathrm{L})$ for $24 \mathrm{~h}$, the cells were stained with $0.5 \mu \mathrm{g} / \mathrm{ml}$ Hoechst 33342 (Life Technologies, USA) for $25 \mathrm{~min}$ at $37^{\circ} \mathrm{C}$. The concentration of DBP in solvent (DMSO) did not exceed $0.5 \%(\mathrm{v} / \mathrm{v})$. Finally, the cells were observed under a fluorescence microscope (Leica, Wetziar, Germany).

\section{Cell Counting Kit-8 (CCK-8)}

Cell proliferation assays were performed using Cell Counting Kit-8 (CCK-8, Dojindo, Kumamoto, Japan) reagents. CCK-8 experiments were carried out for 5 consecutive days by adding $40 \mu \mathrm{l}$ of CCK-8 reagent and $400 \mu \mathrm{l}$ of PBS to each well, with incubation at $37^{\circ} \mathrm{C}$ for $2 \mathrm{~h}$. Viable cells were evaluated by absorbance measurements at $450 \mathrm{~nm}$.

\section{Real-time polymerase chain reaction (real-time PCR)}

Total RNA of kidney tissues and cells was extracted using Trizol reagent (Invitrogen, Carlsbad, CA, USA). Reverse transcript PCR for mRNA was carried out using Superscript II reverse transcriptase and random hexamers (Invitrogen, Carlsbad, CA, USA). $0.8 \mu \mathrm{g}$ mRNA was used for the synthesis of $20 \mu \mathrm{l}$ cDNA. Real-time PCR was performed on an ABI PRISM 7300 Sequence Detection System using SYBR Green PCR (Applied Biosystems). Primer pairs detailed in Table 1.

\section{Immunofluorescence staining}

Paraffin-fixed cells were permeabilized and incubated with a primary antibody overnight at $4^{\circ} \mathrm{C}$, followed by incubated with secondary antibody conjugated 
Table 1: Oligonucleotide primers used in this study

\begin{tabular}{|c|c|c|}
\hline Gene & Forward primer & Reverse primer \\
\hline Foxd1 & TCACTCCTCCCGCGCCCTTC & GCTCCGCTCCGCTACTTGGC \\
\hline$G d n f$ & GGTGTTGCTCCACACCGCGT & GGTGGCCGAGGGAGTGGTCT \\
\hline $\operatorname{Pax} 2$ & CCCAAGGTGGCAACGCCCAA & CGGCGTTGGGTGGAAAGGCT \\
\hline Wnt11 & TCCATCGAGCTCGCCCCCAA & TGGCCCCCATGAGGAGACCG \\
\hline Bmp4 & ACСАССТСААСТСААССААТС & TCCACCACCATCTCCTGATAA \\
\hline Cdh11 & GCCGCCGCCGACTTGTGAAT & ATTTCTGGGGCCGTTGCGGG \\
\hline Calm 1 & GAATGGCACCATTGACTTCC & GTAGCCATTGCCATCCTTGT \\
\hline Cfll & TTCTGGTAGGAGATGTGGGG & ACCAGGTCCTCCTTCTTGCT \\
\hline Ywhac & CCGGTATCTTGCTGAAGTCG & GGATCGGATGTGTAGGTTGC \\
\hline Acta & CGATAGAACACGGCATCATC & CATCAGGCAGTTCGTAGCTC \\
\hline$T g f b$ & TGAGTGGCTGTCTTTTGACG & TGGTTGTAGAGGGCAAGGAC \\
\hline$F n$ & GGGAAGAAAAGGAGCCCAGG & GGAAAAGTCCTGAGGTGGGG \\
\hline Cdknla & CGAGAACGGTGGAACTTTGAC & GAAATCTGTTAGGCTGGTCTGC \\
\hline Gpxl & GGGCAAAGAAGATTCCAGGTT & AGAGCGGGTGAGCCTTCT \\
\hline Cat & $\begin{array}{l}\text { AGGTGACACTATAGAATAGTG } \\
\text { GTTTTCACCGACGAGAT }\end{array}$ & $\begin{array}{l}\text { GTACGACTCACTATAGGGACA } \\
\text { CGAGGTCCCAGTTACCAT }\end{array}$ \\
\hline$G R$ & TTCTGGAACTCGTCCACTAGG & CCATGTGGTTACTGCACTACTTCC \\
\hline Gst & GCCTTCTACCCGAAGACACCTT & GTCAGCCTGTTCCCTACA \\
\hline Gapdh & ACAGCAACAGGGTGGTGGAC & TTTGAGGGTGCAGCGAACTT \\
\hline
\end{tabular}

Abbreviations: forkhead box D1 (Foxd1), glial cell derived neurotrophic factor $(G d n f)$, paired box 2 (Pax2) and winglesstype MMTV integration site family, member 11 (Wnt11), bone morphogenetic protein 4 (Bmp4), cadherin 11 (Cdh11), calmodulin $1(C a l m 1)$, cofilin $1(C f l 1)$, tyrosine 3-monooxygenase/tryptophan 5-monooxygenase activation protein, beta (Ywhab), alpha-smooth muscle actin (Acta), transforming growth factor, beta $(T g f b)$, fibronectin $(F n)$, cyclin-dependent kinase inhibitor 1A $(C d k n 1 a)$, glutathione peroxidase $1(G p x 1)$, catalase $(C a t)$, glutathione reductase $(G R)$ and glutathione-s-transferase (Gst).

to Alexa Fluor 488 or 588 (Molecular Probes, Inc., Eugene, OR, USA). The slides were then counterstained with 4', 6-diamidino-2- phenylindole (DAPI) to visualize the nuclei. Images were obtained using confocal microscopy (TCS SP8; Leica, Wetzlar, Germany). The primary antibodies used in this study included anti-p-H3 (Ser10) (1:1000, Abcam, Cambridge, UK) and anti-Ki67 (1:1000, Abcam, Cambridge, UK).

\section{Measurement of intracellular ROS}

Following treatment with final concentrations of $\operatorname{DBP}(1,10$, or $100 \mu \mathrm{mol} / \mathrm{L})$ for $24 \mathrm{~h}$, cells were incubated with DCFH-DA dye $(50 \mu \mathrm{mol} / \mathrm{L}$, final concentration) in medium for $30 \mathrm{~min}$ in the dark. After rinsing twice with PBS solution, lysis buffer was added to the dishes to disrupt the cell membranes. Cell suspensions were transferred to 96-well plates, and the fluorescence was read at an excitation wavelength of $490 \mathrm{~nm}$ and emission of $520 \mathrm{~nm}$.

\section{Statistical analysis}

Differences were analyzed using Mann-Whitney $U$ test or an independent-samples $t$-test. Stata 7.0 software (Stata Corporation, College Station, USA) was used to analyze all data. Statistical significance was set at $P<0.05$.

\section{Abbreviations}

di-n-butyl phthalate (DBP), tubulointerstitial fibrosis (TIF), postnatal day 1 (PND1), chronic kidney disease (CKD), Developmental Origins of Health and Adult Disease (DOHAD), low birth weight (LBW), 
Environmental endocrine-disrupting compounds (EEDs), anorectal malformations (ARMs), androgen receptor (AR), forkhead box D1 (Foxd1), glial cell derived neurotrophic factor (Gdnf), paired box 2 (Pax2), wingless-type MMTV integration site family, member 11 (Wnt11), bone morphogenetic protein 4 (Bmp4), cadherin 11 (Cdh11), calmodulin 1 (Calm1), tyrosine 3-monooxygenase/ tryptophan 5-monooxygenase activation protein, beta (Ywhab), alpha-smooth muscle actin ( $\alpha$-SMA), transforming growth factor- $\beta$ (TGF- $\beta$ ), phosphorylation of histone $\mathrm{H} 3$ at Ser10 (pH3), reactive oxygen species (ROS), glutathione peroxidase 1 (Gpx1), catalase (Cat), glutathione reductase (GR), glutathione-s-transferase (Gst), gestation day (GD), Dulbecco's modified Eagle's medium (DMEM), fetal bovine serum (FBS), hematoxylin-eosin (H\&E), Cell Counting Kit-8 (CCK-8), Real-time polymerase chain reaction (real-time PCR), 49, 6-diamidino-2- phenylindole (DAPI), standard deviation (SD).

\section{ACKNOWLEDGMENTS}

This work was supported by the National Science Foundation for Young Scientists of China (81000243), National Natural Science Foundation of China (813700041; 81672515), Shanghai Pujiang Program (16PJD039) and Shanghai Health Bureau Research Program (20134423).

\section{CONFLICTS OF INTEREST}

The authors declare that there are no conflicts of interest.

\section{REFERENCES}

1. Jha V, Garcia-Garcia G, Iseki K, Li Z, Naicker S, Plattner B, Saran R, Wang AY, Yang CW. Chronic kidney disease: global dimension and perspectives. Lancet. 2013; 382:260-72.

2. Boor P, Ostendorf T, Floege J. Renal fibrosis: novel insights into mechanisms and therapeutic targets. Nat Rev Nephrol. 2010; 6:643-56.

3. Liu Y. Cellular and molecular mechanisms of renal fibrosis. Nat Rev Nephrol. 2011; 7:684-96.

4. Zeisberg M, Neilson EG. Mechanisms of tubulointerstitial fibrosis. J Am Soc Nephrol. 2010; 21:1819-34.

5. Visentin S, Grumolato F, Nardelli GB, Di Camillo B, Grisan E, Cosmi E. Early origins of adult disease: low birth weight and vascular remodeling. Atherosclerosis. 2014; 237:391-99.

6. Barker DJ. Fetal origins of coronary heart disease. BMJ. 1995; 311:171-74.

7. Barker DJ. The fetal and infant origins of adult disease. BMJ. 1990; 301:1111

8. Yajnik CS, Deshpande SS, Panchanadikar AV, Naik SS, Deshpande JA, Coyaji KJ, Fall C, Refsum H. Maternal total homocysteine concentration and neonatal size in India. Asia Pac J Clin Nutr. 2005; 14:179-81.

9. Dalman C, Allebeck P, Gunnell D, Harrison G, Kristensson K, Lewis G, Lofving S, Rasmussen F, Wicks S, Karlsson $\mathrm{H}$. Infections in the CNS during childhood and the risk of subsequent psychotic illness: a cohort study of more than one million Swedish subjects. Am J Psychiatry. 2008; 165:59-65.

10. Simmons RA, Suponitsky-Kroyter I, Selak MA. Progressive accumulation of mitochondrial DNA mutations and decline in mitochondrial function lead to beta-cell failure. J Biol Chem. 2005; 280:28785-91.

11. Ho SM, Tang WY, Belmonte de Frausto J, Prins GS. Developmental exposure to estradiol and bisphenol A increases susceptibility to prostate carcinogenesis and epigenetically regulates phosphodiesterase type 4 variant 4 . Cancer Res. 2006; 66:5624-32.

12. Li S, Chen SC, Shlipak M, Bakris G, McCullough PA, Sowers J, Stevens L, Jurkovitz C, McFarlane S, Norris K, Vassalotti J, Klag MJ, Brown WW, et al. Low birth weight is associated with chronic kidney disease only in men. Kidney Int. 2008; 73:637-42.

13. Hallan S, Euser AM, Irgens LM, Finken MJ, Holmen J, Dekker FW. Effect of intrauterine growth restriction on kidney function at young adult age: the Nord Trøndelag Health (HUNT 2) Study. Am J Kidney Dis. 2008; 51:10-20.

14. Pan G, Hanaoka T, Yoshimura M, Zhang S, Wang P, Tsukino H, Inoue K, Nakazawa H, Tsugane S, Takahashi $\mathrm{K}$. Decreased serum free testosterone in workers exposed to high levels of di-n-butyl phthalate (DBP) and di-2ethylhexyl phthalate (DEHP): a cross-sectional study in China. Environ Health Perspect. 2006; 114:1643-48.

15. Ema M, Miyawaki E, Kawashima K. Critical period for adverse effects on development of reproductive system in male offspring of rats given di-n-butyl phthalate during late pregnancy. Toxicol Lett. 2000; 111:271-78.

16. Foster PM, Cattley RC, Mylchreest E. Effects of di-n-butyl phthalate (DBP) on male reproductive development in the rat: implications for human risk assessment. Food Chem Toxicol. 2000; 38:S97-99.

17. Mylchreest E, Wallace DG, Cattley RC, Foster PM. Dose-dependent alterations in androgen-regulated male reproductive development in rats exposed to Di(n-butyl) phthalate during late gestation. Toxicol Sci. 2000; 55:143-51.

18. Carruthers CM, Foster PM. Critical window of male reproductive tract development in rats following gestational exposure to di-n-butyl phthalate. Birth Defects Res B Dev Reprod Toxicol. 2005; 74:277-85.

19. Foster PM. Disruption of reproductive development in male rat offspring following in utero exposure to phthalate esters. Int J Androl. 2006; 29:140-47.

20. Jiang J, Ma L, Yuan L, Wang X, Zhang W. Study on developmental abnormalities in hypospadiac male rats 
induced by maternal exposure to di-n-butyl phthalate (DBP). Toxicology. 2007; 232:286-93.

21. Kim TS, Jung KK, Kim SS, Kang IH, Baek JH, Nam HS, Hong SK, Lee BM, Hong JT, Oh KW, Kim HS, Han SY, Kang TS. Effects of in utero exposure to DI(n-Butyl) phthalate on development of male reproductive tracts in Sprague-Dawley rats. J Toxicol Environ Health A. 2010; 73:1544-59.

22. Jiang JT, Sun WL, Jing YF, Liu SB, Ma Z, Hong Y, Ma L, Qin C, Liu Q, Stratton HJ, Xia SJ. Prenatal exposure to din-butyl phthalate induces anorectal malformations in male rat offspring. Toxicology. 2011; 290:322-26.

23. Jiang JT, Zhong C, Zhu YP, Xu DL, Wood K, Sun WL, Li EH, Liu ZH, Zhao W, Ruan Y, Xia SJ. Prenatal exposure to di-n-butyl phthalate (DBP) differentially alters androgen cascade in undeformed versus hypospadiac male rat offspring. Reprod Toxicol. 2016; 61:75-81.

24. Zhu YP, Li EH, Sun WL, Xu DL, Liu ZH, Zhao W, Wood K, Xia SJ, Jiang JT. Maternal exposure to di-n-butyl phthalate (DBP) induces combined anorectal and urogenital malformations in male rat offspring. Reprod Toxicol. 2016; 61:169-76.

25. Liu ZH, Li EH, Xu DL, Sun WL, Hong Y, Zhao W, Xia SJ, Jiang JT. Genetic research and structural dysplasia assessment of anorectal malformations in neonatal male rats induced by di(n-butyl) phthalate. Environ Toxicol. 2016; 31:261-68.

26. Nyengaard JR, Bendtsen TF. Glomerular number and size in relation to age, kidney weight, and body surface in normal man. Anat Rec. 1992; 232:194-201.

27. Jiang JT, Xu HL, Zhu YP, Wood K, Li EH, Sun WL, Yuan Q, Xu DL, Liu ZH, Zhao W, Xia SJ. Reduced Fgf10/Fgfr2 and androgen receptor (AR) in anorectal malformations male rats induced by di-n-butyl phthalate (DBP): A study on the local and systemic toxicology of DBP. Toxicology. 2015; 338:77-85.

28. Johnson DG, Walker CL. Cyclins and cell cycle checkpoints. Annu Rev Pharmacol Toxicol. 1999; 39: 295-312.

29. Wei Z, Song L, Wei J, Chen T, Chen J, Lin Y, Xia W, Xu B, Li X, Chen X, Li Y, Xu S. Maternal exposure to di-(2- ethylhexyl)phthalate alters kidney development through the renin-angiotensin system in offspring. Toxicol Lett. 2012; 212:212-21.

30. Aly HA, Hassan MH, El-Beshbishy HA, Alahdal AM, Osman AM. Dibutyl phthalate induces oxidative stress and impairs spermatogenesis in adult rat. Toxicol Ind Health. 2016; 32:1467-1477.

31. Heierhorst J, Smyth I, Jurado S. A breathtaking phenotype: unexpected roles of the DNA base damage response protein ASCIZ as a key regulator of early lung development. Cell Cycle. 2011; 10:1222-24.

32. Hassan ZK, Elobeid MA, Virk P, Omer SA, ElAmin M, Daghestani MH, AlOlayan EM. Bisphenol A induces hepatotoxicity through oxidative stress in rat model. Oxid Med Cell Longev. 2012; 2012:194829.

33. Farris AB, Colvin RB. Renal interstitial fibrosis: mechanisms and evaluation. Curr Opin Nephrol Hypertens. 2012; 21:289-300.

34. Chang DK, Goel A, Ricciardiello L, Lee DH, Chang CL, Carethers JM, Boland CR. Effect of $\mathrm{H}(2) \mathrm{O}(2)$ on cell cycle and survival in DNA mismatch repair-deficient and -proficient cell lines. Cancer Lett. 2003; 195:243-51.

35. Yang L, Besschetnova TY, Brooks CR, Shah JV, Bonventre JV. Epithelial cell cycle arrest in G2/M mediates kidney fibrosis after injury. Nat Med. Nat Med. 2010; 16:535-43, 1p following 143 .

36. Gangadharan B, Murugan MA, Mathur PP. Effect of methoxychlor on antioxidant system of goat epididymal sperm in vitro. Asian J Androl. 2001; 3:285-88.

37. Korkmaz A, Kolankaya D. The protective effects of ascorbic acid against renal ischemia-reperfusion injury in male rats. Ren Fail. 2009; 31:36-43.

38. Sirmali R, Armağan A, Öktem F, Uz E, Kirbas A, Dönmezs S, Yilmaz HR, Silay MS, Sirmali M. Protective effects of erdosteine, vitamin $\mathrm{E}$, and vitamin $\mathrm{C}$ on renal injury induced by the ischemia-reperfusion of the hind limbs in rats. Turk J Med Sci. 2015; 45:33-37. 